\title{
A Low-Cost Electrical Rotary Machinery Fault Detector
}

\author{
Omar Hernández, BS ${ }^{1}$, Carlos Martínez, BS ${ }^{2}$, Pedro Anibarro, Bs ${ }^{1}$, Héctor Rodríguez ${ }^{1}, \mathrm{PhD}$, Miguel Labrador ${ }^{2}, \mathrm{PhD}$, \\ and Idalides Vergara, $\mathrm{PhD}$ \\ ${ }^{1}$ Universidad Ana G. Méndez, Gurabo, Puerto Rico, ohernandez34@email.suagm.edu, CMARTINEZ117@email.suagm.edu, \\ panibarro1@email.suagm.edu, hrodriguez183@suagm.edu, ivergara@suagm.edu \\ ${ }^{2}$ University of South Florida, USA, mlabrador@usf.edu
}

\begin{abstract}
Nowadays, electrical rotary machinery is widely used in production lines, turning machines, ventilation and air conditioning systems. For continuous production and reliability, vibration analysis is commonly used for maintenance and failure detection. There are several tools that help users to diagnose faults but cannot be used due to high costs and other limitations. This project presents a low-cost diagnostic system for electrical rotaries based on vibration analysis. The proposed system includes a vibration sensing device, which is placed in each machine, containing a low cost accelerometer, an amplification circuit, and a microcontroller that sends the data to an Android application using Bluetooth technology. After receiving the data, the Android application computes the Fast Fourier Transform, and analyzes these data in order to detect and identify the fault. Once the fault is identified, it is displayed in the application along with a set of useful recommendations to repair the machine, prevent major degradation and or damages. The Android application also gives the user the option to save the diagnostics and see a history of previous reports for any registered machine.
\end{abstract}

\section{INTRODUCTION}

Safety and reliability are critical requirements for industry machinery. They reduce costs, decrease the machine downtime and increase the safety for machine and humans. In conditionbased maintenance, vibration analysis is one of the most effective to detect and diagnose machine failures [1]. Although there are devices to diagnose machine failures, they are too expensive, increasing the cost of machine maintenance.

Having a machine in good condition is very important in the industrial field. Failures of industrial machines can cause real damage to the company of the owner. This can be from cost of reparation and services up to company reputation among other things. For example, a company that generates $\$ 200,000$ in gross profit for each hour of production of a machine. If the machine needs to be stopped because of some failure for 2 days, waiting for the new piece to arrive and repairing time, the company would lose $\$ 9,600,000$ in just 2 days. Now, add to that the repair cost and that the company needs to meet customer demand. The company may face customer loss since they cannot meet the deadlines, and this can escalate quickly and damage the company reputation. So, it is very important to understand how important is to have an industrial machine running. The company should know the status of its machines in order to prevent any damage [3].

Digital Object Identifier (DOI):

http://dx.doi.org/10.18687/LACCEI2019.1.1.397

ISBN: 978-0-9993443-6-1 ISSN: 2414-6390
Saying that, there are devices that can diagnose machine failures without the need to stop operations. There are several ways to diagnose machine failures, but vibrations analysis is one of the most used technique. Devices that uses this technique cost a lot of money. Fluke Corporation for example, have several devices for diagnosis of machinery faults. The problem of this devices is that their cost range is from $\$ 2,000$ to $\$ 10,000$. This means that it is very expensive to buy several of devices in order to know your machinery status. Another problem with this device is that you cannot have a status of your machine anytime and remotely because they are not meant to be used constantly.

There are numerous causes that could be listed for machinery failure. Some faults might arise from particularly aggressive service environments or operating conditions or just by normal damage that occurs over time of usage. These are some of the most common machinery faults [4]:

- Misalignment

- Unbalance

- Resonance

- Bearings

- Looseness

- Electrical

- Bent Shaft

- Gear Mesh

This paper proposes an inexpensive solution to diagnose rotating machinery using an inexpensive accelerometer connected to a microprocessor which is transmitting data to a mobile device via Bluetooth, captures vibration data and uses the Fast Fourier Transform algorithm in order to diagnose machine failures such as mass unbalance and bent shaft. This device has the potential to save thousands of dollars by giving the user an inexpensive solution to diagnose their machines anytime, remotely, and in real time by being cheap enough to buy more than one device to build a whole network to diagnose several machines at the same time reducing the probabilities of machinery faults.

The rest of the paper is organized as follows: Section II describes the basic knowledge needed to analyze the vibrations and the Fast Fourier Transform. Section III presents the proposed solution. Section IV shows the results and the evaluation of our system. Finally, Section V concludes the paper and explains future research.

$17^{\text {th }}$ LACCEI International Multi-Conference for Engineering, Education, and Technology: "Industry, Innovation, And Infrastructure for Sustainable Cities and Communities", 24-26 July 2019, Jamaica. 


\section{RELATED WORK}

Machines produce some oscillatory motion as part of their normal operation, and these are nothing to be concerned about [6]. Saying that, a malfunctioning motor also can be reflected in its vibrations. These anomalies can tell the data analyst much information about the status of the machine. Therefore, we can say that there are benign and bad vibrations. The benign vibrations are characteristic of a regular operation of a machine doing what it is supposed to do. Any change above this normal operation is a reason to investigate the situation. In order to diagnose a machine, the machine frequency needs to be analyzed. The frequency is the key information that establishes the possible causes and then its amplitude is used to judge the severity. The algorithm used to analyze the frequency generated by the vibrations of the machine is the FFT (Fast Fourier Transform). The Fast Fourier Transform (FFT) is an algorithm optimization of the Discrete Fourier Transform (DFT). The DFT is extremely important in the area of frequency analysis because it takes a discrete signal in the time domain and transforms that signal into its discrete frequency domain representation [7]. It has many applications and uses. Saying that, we choose to use FFT for spectral analysis because is a faster version of the DFT. We are going to use it to find the frequency components of a signal buried in a noisy time domain signal. The mathematical model for the FFT is showed in Equation 1[8].

$f(t)=a_{0}+\sum_{n=1}^{\infty}\left(a_{n} \cos (\mathrm{nt})+b_{n} \sin (n t)\right)$

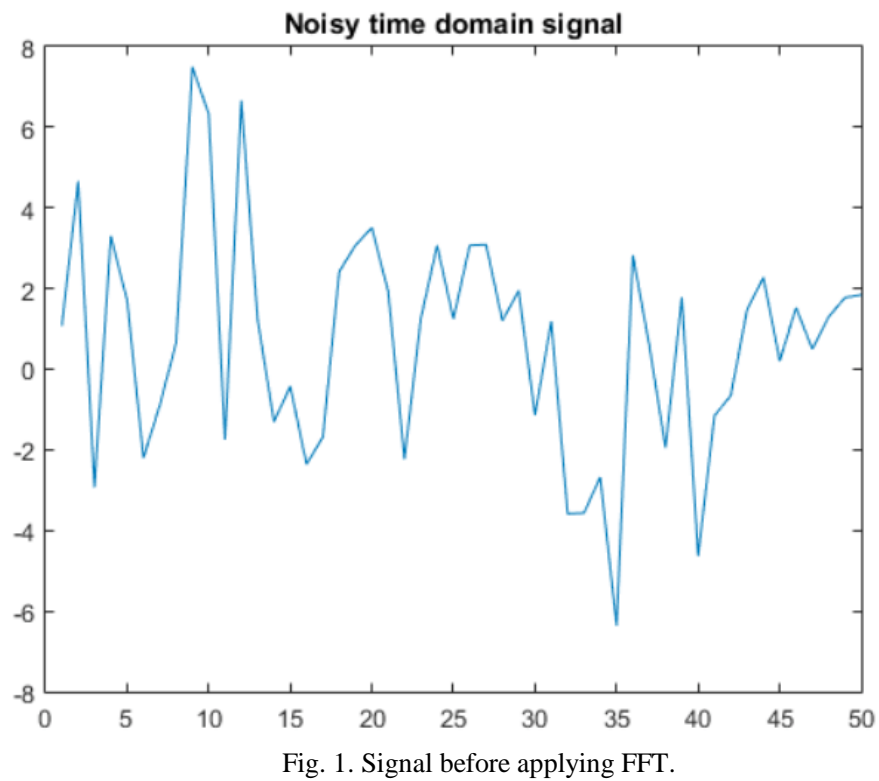

The coefficients an and bn are called Fourier coefficients. The job of a Fourier Transform is to figure out all the $a_{n}$ and $b_{n}$ values to produce a Fourier Series, given the base frequency and the function $f(t)$. Let's take for example a signal that contains sine waves at $50 \mathrm{~Hz}$ and $120 \mathrm{~Hz}$ [9]. We add some random noise and get Figure 1 (amplitude versus time).

We can see that it is difficult to identify the frequency components by just looking at this signal. This is why the FFT is so popular in spectral analysis. After we apply the FFT to this signal we get Figure 2 (amplitude versus frequency).

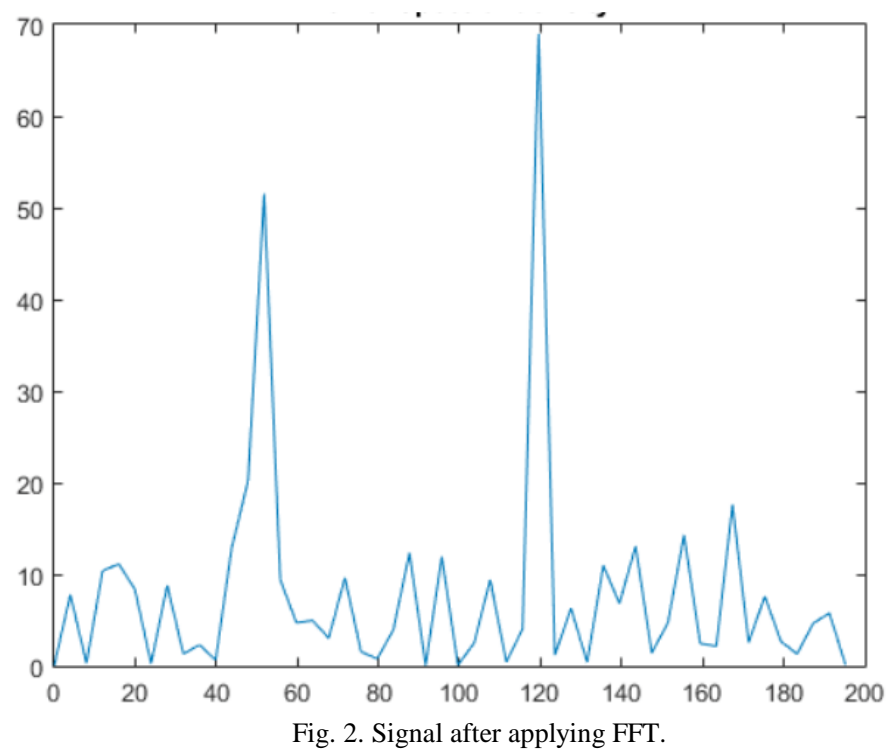

Notice the peaks at $50 \mathrm{~Hz}$ and $120 \mathrm{~Hz}$ in Figure 2. We can see that the FFT cleans our signal and is capable of identifying our frequencies of the original signal. Two people can view the same data and come to different conclusions [10]. In this application, we need to know what the FFT graph means. There are diagnostic charts that aid in this process. Table I shows the different faults that a machinery can have depending on the frequency and amplitude processed by the FFT [11]. This table is used to diagnose machinery faults in our system. We are using the open source FFT implementation of Princeton University because it is written in Java and it is accessible. [12]. 
Table I. Common Machinery Fault

\begin{tabular}{|c|c|c|}
\hline Fault & Frequency & Spectrum \\
\hline $\begin{array}{l}\text { Mass } \\
\text { unbalance }\end{array}$ & $1 X$ & $\begin{array}{l}\text { Distinct } 1 X \text { with much } \\
\text { lower values of } 2 X, 3 X \text {, } \\
\text { etc. }\end{array}$ \\
\hline Misalignment & $1 \mathrm{X}, 2 \mathrm{X}$, etc. & $\begin{array}{l}\text { Distinct } 1 X \text { with much } \\
\text { lower values of } 2 X, 3 X \text {, } \\
\text { etc. }\end{array}$ \\
\hline Shaft bow & $1 X$ & $\begin{array}{l}\text { Dropout of vibration } \\
\text { around critical speed } \\
\text { in Bode plot }\end{array}$ \\
\hline Bearing wear & $\begin{array}{l}\text { 1X, subharmonics, } \\
\text { orders }\end{array}$ & $\begin{array}{l}\text { High } 1 \mathrm{X} \text {, high } 1 / 2 \mathrm{~h} \mathrm{X} \text {, } \\
\text { sometimes } 11 / 2 \text { or } \\
\text { orders }\end{array}$ \\
\hline $\begin{array}{l}\text { Gravity } \\
\text { excitation }\end{array}$ & $2 X$ & $\begin{array}{l}1 / 2 \text { critical speed } \\
\text { appears on Bode } \\
\text { plot(unfiltered) }\end{array}$ \\
\hline $\begin{array}{l}\text { Asymmetric } \\
\text { rotor }\end{array}$ & $2 X$ & $\begin{array}{l}1 / 2 \text { critical speed } \\
\text { appears on Bode } \\
\text { plot(unfiltered) }\end{array}$ \\
\hline $\begin{array}{l}\text { Cracked } \\
\text { rotor }\end{array}$ & $1 X, 2 X$ & $\begin{array}{l}\text { High } 1 \mathrm{X}, 12 \text { critical } \\
\text { speeds may show up } \\
\text { on coast-down }\end{array}$ \\
\hline Looseness & $\begin{array}{l}\text { 1X plus large numbers of } \\
\text { orders, } 1 / 2 X \text { may show } \\
\text { up }\end{array}$ & $\begin{array}{l}\text { High } 1 \mathrm{X} \text { with lower- } \\
\text { level orders, large } 1 / 2 \\
\text { order }\end{array}$ \\
\hline $\begin{array}{l}\text { Coupling } \\
\text { lockup }\end{array}$ & $1 X, 2 X, 3 X$, etc. & $\begin{array}{l}1 \mathrm{X} \text { with high } 2 \mathrm{X} \text { similar } \\
\text { to misalignment }\end{array}$ \\
\hline $\begin{array}{l}\text { Thermal } \\
\text { instability }\end{array}$ & $1 X$ & $\begin{array}{l}1 \mathrm{X} \text { has varying phase } \\
\text { angle and amplitude }\end{array}$ \\
\hline
\end{tabular}

\section{DESIGN}

This project performs a remotely diagnose in electrical rotary machines at low cost and without requiring technical knowledge. This system defines two major components: a vibration sensing device and an Android application. This section presents the proposed architecture, the vibration sensing device, and the

\section{A. Proposed architecture}

The proposed system, using an inexpensive accelerometer connected to a microprocessor which is transmitting data to a mobile device via Bluetooth, captures vibration data and uses the Fast Fourier Transform algorithm in order to diagnose machine failures such as unbalancing. In addition to reducing costs, at the same time our device was designed with the idea of creating a network with several of these devices so that they can be accessed remotely anytime with a mobile application as showed in Figure 3. In this figure, there are three rotational machines; a Vibration Sensing Device, composed by a accelerometer, an instrumental amplifier, a microcontroller and a Bluetooth device is placed on. Then, the user can select a machine for diagnosis using an Android Tablet. This scheme allows a company to test each rotational machine in site.

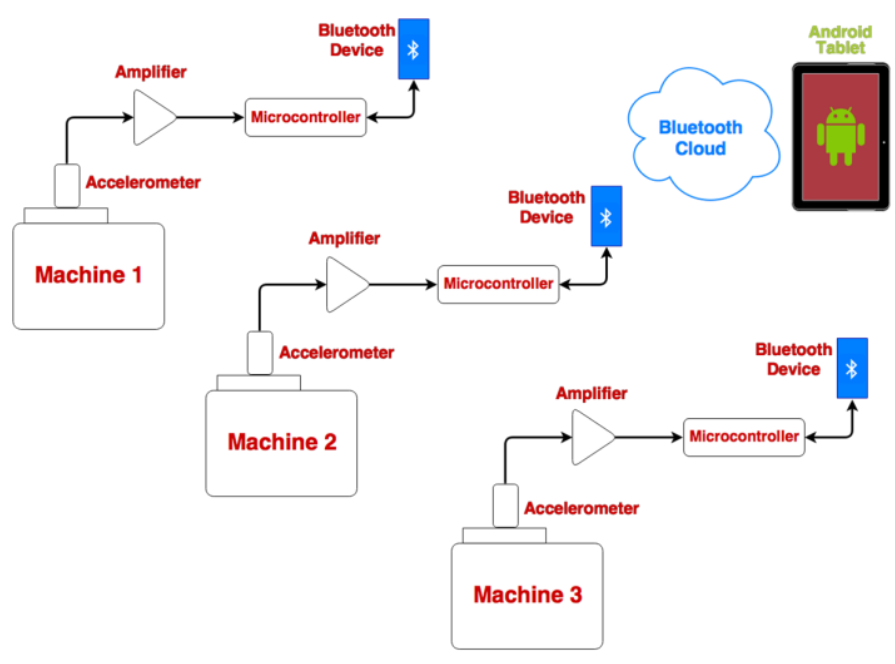

Fig. 3 Proposed architecture.

\section{B. Vibration Sensing Device}

The main purpose of this hardware is to sense the vibrations of the machine using a low cost 3-axial accelerometer which is placed close to the shaft. The output of the accelerometer is amplified so the microcontroller can read it. The data is stored in microcontroller's RAM and then sent to the Android application which analyze the data and performs the diagnosis. Algorithm 1 shows the data collection process using the vibration sensing device - VSD. Once the machine is selected, the VSD uses the accelerometer to collect 3-axis data which is stored in the micro SD card. The VSD transfer all data when required, and finally it is disconnected from the mobile application.

The amplifying circuit achieved to amplify signals between the cutoff frequencies and cut the others. It also maintains the output voltage between $3.3 \mathrm{~V}$ and $0 \mathrm{~V}$ if the input signal has a bigger amplitude than expected.

\begin{tabular}{l}
\hline ALGORITHM 1: Collect data from micro-controller \\
\hline 1: Collect data from accelerometer \\
2: Saves it to micro SD card \\
3: Connect to mobile device \\
5: Transfer all data \\
6: Disconnect from mobile device \\
\hline
\end{tabular}

\section{Fault analysis phase}

The android application allows the user to add/select a machine to diagnose, enter the required information and send

$17^{\text {th }}$ LACCEI International Multi-Conference for Engineering, Education, and Technology: "Industry, Innovation, And 
the command to the device to start the test. Algorithm 2 shows the analysis and diagnosis phases in the system.

Once the mobile device received the actual data from the VSD, itis processed to apply the FFT in order to generate the $\mathrm{X}$ axis FFT. It removes the FFT mirror output and finds the peaks of the FFT output. The application compares the results with the faults characterized in Table I. Once the diagnosis is completed the result are displayed. The user will have the option to save the diagnosis or dismiss the results.

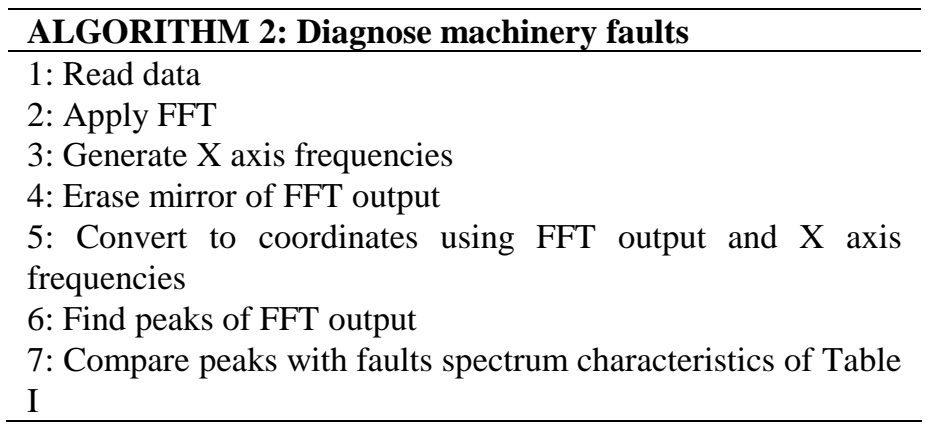

\section{Android Application Interface}

Fig 4. Shows the application main activity. In this activity, the user can turn-on the Bluetooth connection, add a new machine to the system, select a machine to performance the diagnosis and check the diagnostic history for a machine.

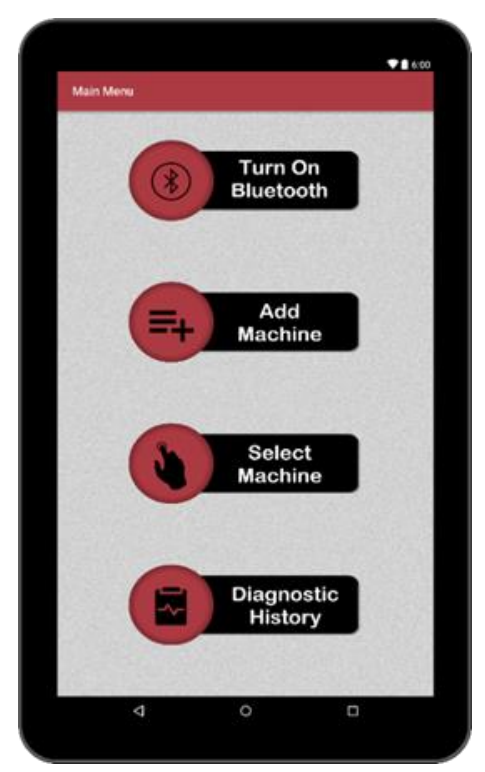

Fig. 4 Main activity.

Once a machine is selected for diagnosis, a new activity is opened as shown in Fig. 5. In this activity, the user must register the machine rotational frequency and critical frequencies.

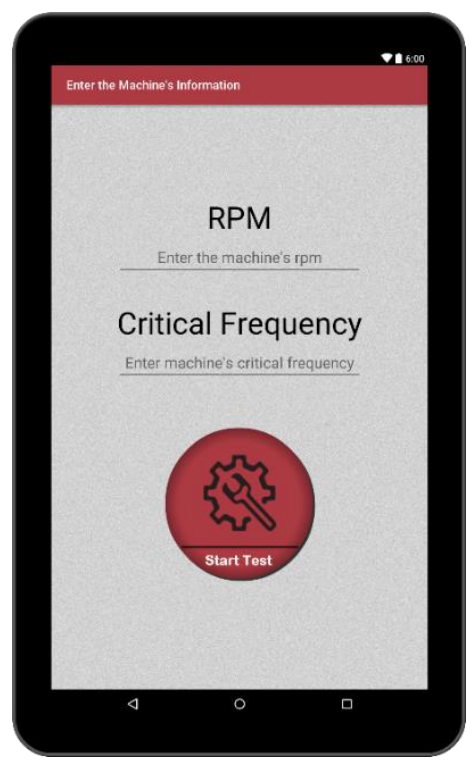

Fig. 5 Machine required data

Once the diagnostic is performed, the application shows a new activity with the results. Fig. 6. Shows an example of this. In this example the system found a Mass Unbalance problem, and recomends to add a mas to the less heavy side in order to balance the machine.

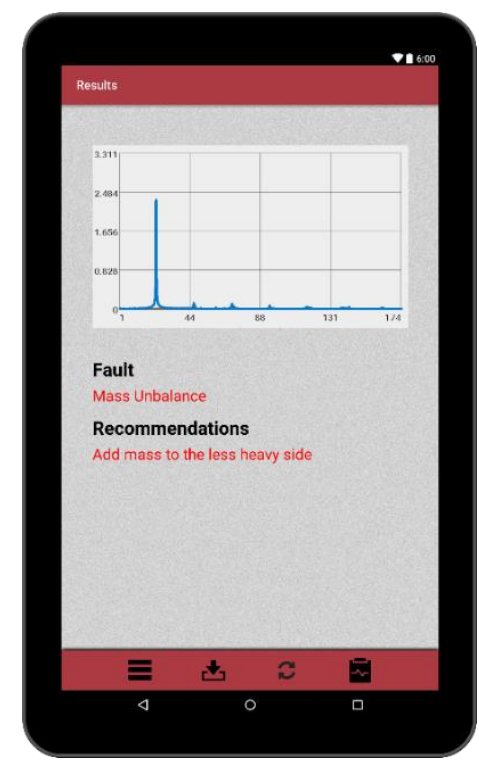

Fig. 5 Machine required data

Finally, in fig. 6. the result history is shown. The user is able to acces the diagnosis history for each machine including the date and time. In this way, the mainteniance schedule could be improved based on the machine's historical data. 


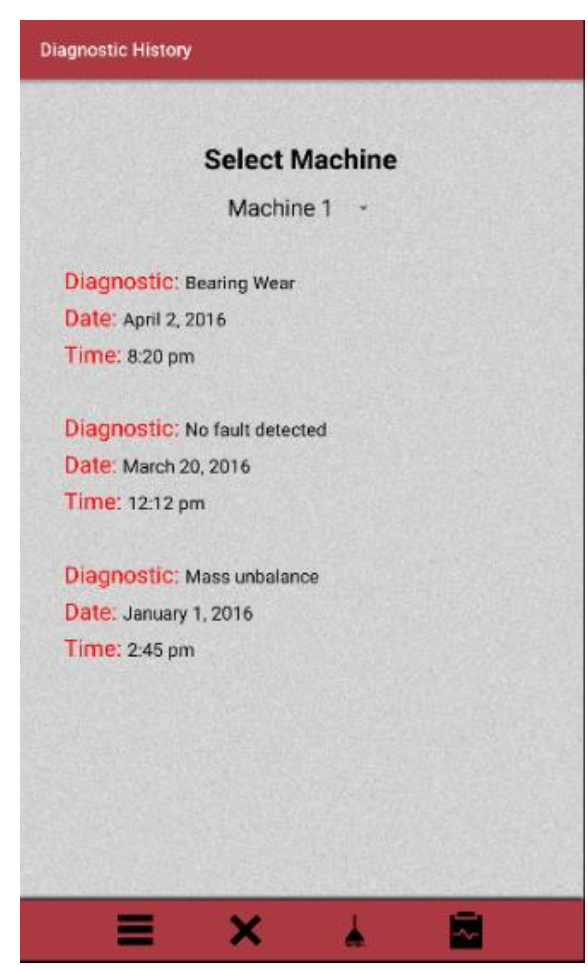

Fig. 6 Historical data

\section{RESULTS}

The actual circuit implementation is shown in Fig. 7. The actual elements include an Arduino Due, an ADXL335 accelerometer, an AD620 instrumental amplifier, a LM7805 voltage regulator, and a $\mathrm{HC}-05$ Bluetooth transmitter.

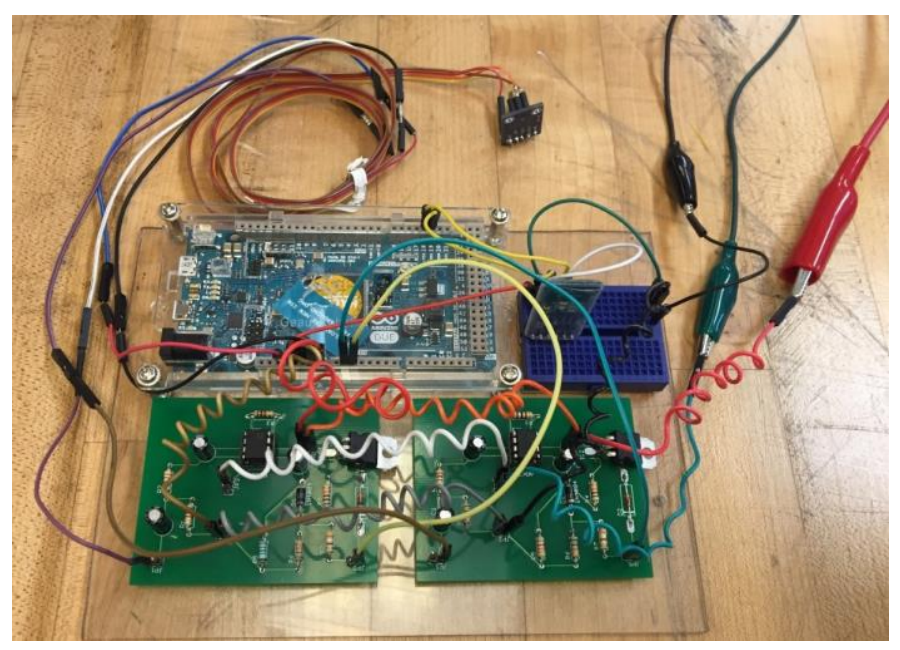

Fig. 7 Actual circuit

In addition, this section presents the actual tests and fault detection scenarios performed in this work, including no fault, unbalance, and bent shaft. For these tests a machine fault simulator model VFD007S11B was used. Its critical frequency is 3600 .

\section{A. No fault}

This test was perform using 1229rpm and 984rpm on the machine fault simulator. As shown on Fig. 8, there are not predominant peaks in the vibration spectrum.

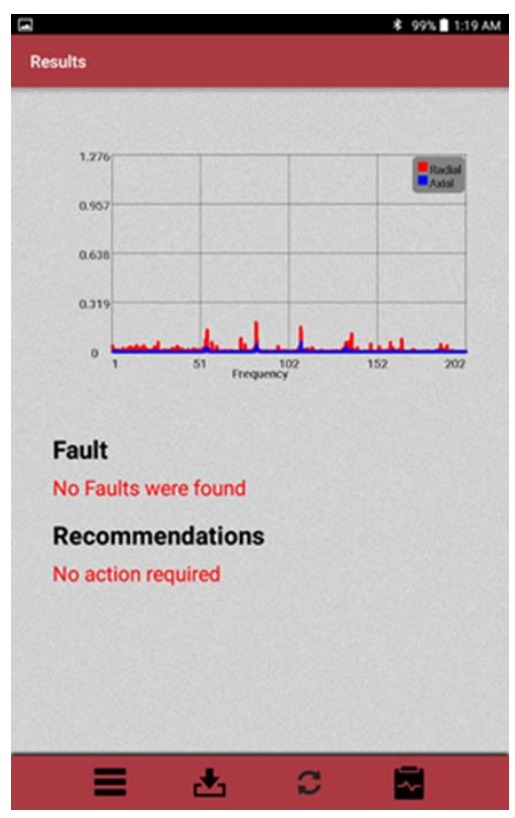

Fig. 8. No fault at $984 \mathrm{rpm}$.

B. Unbalance test

In order to simulate and mass unbalance fault, a mass of $4.3052 \mathrm{~g}$ was placed 3 inches from the shaft. The testing the rotational frequency was set to $1254 \mathrm{rpm}$ which is equivalent to $20.9 \mathrm{~Hz}$.

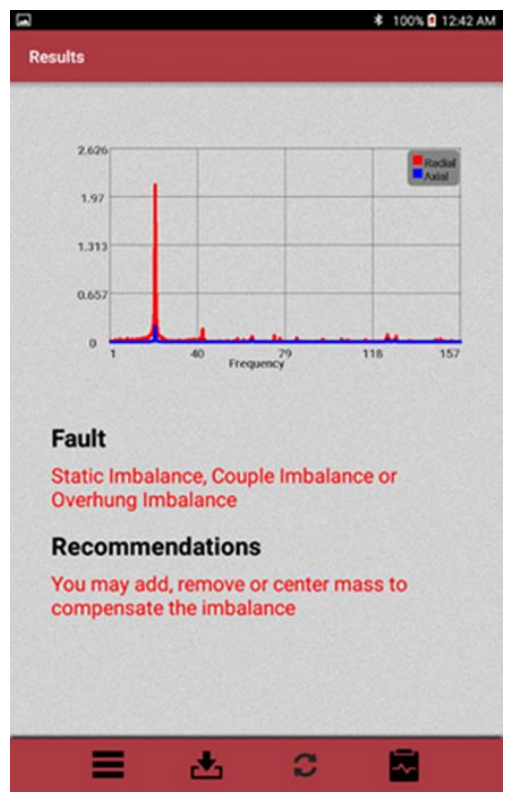

Fig. 9. Mass unbalance at $1254 \mathrm{rpm}$. 
Fig. 9 shows a peak at $20 \mathrm{~Hz}$, consequently the system diagnosed a fault of mass unbalance and recommends add, remove, or center to compensate the unbalance.

In addition, other tests were performed at $1544 \mathrm{rpm}$; in this case a dominant peak appears at $25.73 \mathrm{~Hz}$ which is the rotor frequency. The system diagnoses the mass unbalance fault, and recommends to add, remove or center mass to compensate the unbalance.

\section{Bent shaft}

In order to simulate the bent shaft, two bent shafts were mounted to the Machine Fault simulator. A bent shaft typically produces spectra that have misalignment type characteristics. According to table I, the system must have dominant peaks at $1 \mathrm{X}, 2 \mathrm{X}$, and $3 \mathrm{X}$ in the axial spectrum. The tests were performed at 1676rpm and 1836rpm. Fig. 10 shows results for 1676rpm $(27.9 \mathrm{~Hz})$; as you can notice, there are peaks at $1 \mathrm{x}$, $2 \mathrm{x}$, and $3 \mathrm{x}$, which corresponds to the bent shaft fault. In addition, the system recommends to straight or replace it.

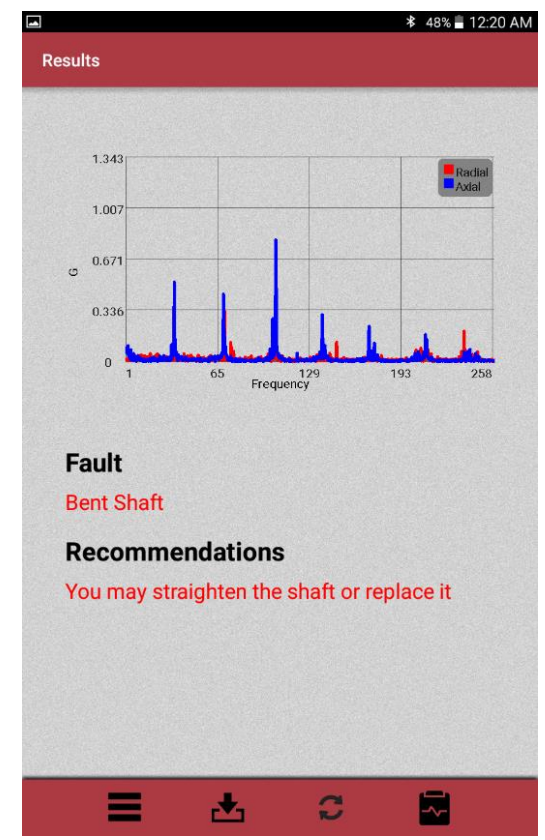

Fig. 10. Bent shaft at $1676 \mathrm{rpm}$.

\section{CONCLUSIONS}

This paper proposes an inexpensive system to diagnose machinery faults using an Arduino with external accelerometers and an Android base mobile application. The system uses the Fast Fourier Transform algorithm in order to do spectrum analysis to the vibration data gathered by the external accelerometer. A series of algorithms and techniques in conjunction with a common machinery faults spectrum table is used to diagnose a machine fault. The system low-cost allows it to be installed in any rotational equipment in order to detect faults. The android application allows the maintenance team to check periodically, and remotely, each rotational machine where the vibration sensing device is installed. The tests performed in this project diagnosed successfully no faults, mass unbalance, and bent shafts to rotary machinery.

As future work, the input of the RPM's to the Application could be obtained and sent by the hardware with additional components and programming.

\section{ACKNOWLEDGMENT}

NSF for partially supporting this research under grant No. 1458928, An REU Site on Ubiquitous Sensing at University of South Florida.

\section{REFERENCES}

[1] M. Nakhaeinejad and D. O. Bukowitz, "Practical Vibration Analysis of Machinery: Case Studies". Createspace Independent Pub, 2011.

[2] Warrantydirect.co.uk, "German manufacturers amongst least reliable for engines,"

[3] M. Ozkok, "The effects of machine breakdown on hull structure production process," Scientia Iranica, 2013.

[4] P. Brown, "Using Vibration Analysis for Machinery Fault Diagnosis", lifetime reliability solutions, 2015.

[5] Arduino Group Turabo, "Accelerometer with LCD and SD."

[6] V. Wowk, "A Brief Tutorial on Machine Vibration"

[7] J. Hansen, "FFT Tutorial," 2010.

[8] L. Vas, "Fourier Series. Fourier Transform," 2007.

[9] Mathworks.com, "FFT for Spectral Analysis."

[10] B. Ninness, "Spectral Analysis using the FFT."

[11] F. F. Ehrich, Handbook of Rotordynamics. 2004.

[12] Princeton University, "FFT Implementation."

[13] Commtest.com, "Beginner's Guide to Machine Vibration,"

$17^{\text {th }}$ LACCEI International Multi-Conference for Engineering, Education, and Technology: "Industry, Innovation, And 